\title{
Geometric morphometrics as a tool for three species identification of the firefly (Coleoptera: Lampyridae) in Thailand
}

\author{
SUCHADA SUMRUAYPHOL ${ }^{1}$, TANAWAT CHAIPHONGPACHARA ${ }^{2, \bullet}$ \\ ${ }^{1}$ Department of Medical Entomology, Faculty of Tropical Medicine, Mahidol University, Bangkok 10400, Thailand \\ ${ }^{2}$ Department of Public Health and Health Promotion, College of Allied Health Science, Suan Sunandha Rajabhat University.Samut Songkhram 75000, \\ Thailand. Tel./fax. +66-835-865775, Corresponding Author”email: tanawat.ch@ @sru.ac.th
}

Manuscript received: 8 July 2019. Revision accepted: 29 July 2019.

\begin{abstract}
Sumruayphol S, Chaiphongpachara T. 2019. Geometric morphometrics as a tool for three species identification of the firefly (Coleoptera: Lampyridae) in Thailand. Biodiversitas 20: 2388-2395. Firefly is an insect belonging to the Lampyridae family that is important to the ecosystem, generates income from tourism in the area and act as a biological control for snail, an intermediate hosts of trematode parasites. Some types of the firefly, it is difficult to distinguish the species using standard methods because of similarities in morphology while the external characteristics of specimens are damaged during collection, presenting an obstacle to species identification. This study used geometric morphometrics (GM) for identification of firefly species. Samples collection was conducted in the rainy season from August to October 2015 in three districts of Samut Songkham province, Thailand. A total of 200 and 157 fireflies from 3 genera and four species, including Luciola aquatilis Thancharoen, Pteroptyx valida Olivier, Pteroptyx malaccae Gorham and Pyrocoelia praetexta Olivier were used for landmark-based and outline-based GM analysis, respectively. The results showed that both types of GM analysis produced similar results, size variation between two firefly pairs was not statistically significant, including female L. aquatilis with male $P$. praetexta, and female $P$. valida with male $P$. valida. Both landmark-based and outline-based GM methods can distinguish the shape for each type of firefly with high accuracy, especially the outline-based GM method. This result was supported by reclassification scores. According to our findings, the GM can be used to separate species of fireflies with high efficiency. Therefore, this GM method represents one way of overcoming difficulties with firefly identification and can support future studies of fireflies.
\end{abstract}

Keywords: Geometric morphometrics, species identification, firefly

\section{INTRODUCTION}

Firefly is a beetle belonging to the Lampyridae family, order Coleoptera (Madruga and Hernández 2010). There are five subfamilies of the firefly, including Amydetinae Olivier, Lampyrinae Rafinesque, Luciolinae Lacordaire, Photurinae Lacordaire, and Psilocladinae McDermott, and more than 2000 species of firefly around the world (Bousquet 1991). It is classified as an insect species which has high diversity. They are nocturnal insects, but in the daytime are often hidden in the ground (Foo et al. 2015). Fireflies have the ability to create light by an abdominal light organ, acting as a signal for mating (Goh et al. 2013). This feature makes fireflies a focus for humans, with tours conducted to observe them, contributing to the income of people living in the area (Nurancha et al. 2013). Fireflies are also important indicators of the integrity of the environment. Moreover, it has been reported that the firefly is a biological control method for trematode parasites because firefly larvae eat snails which act as the intermediate host of the trematode worm $(\mathrm{Fu}$ and Benno 2013; Wang et al. 2007). Although fireflies are highly diverse and important in nature, there are few research studies that relate to them.

Thailand is one of the tropical countries where fireflies are widely distributed and many species exist (Nurancha et al. 2013). The insects also occur in large numbers, making it challenging to identify the correct scientific name as they have highly similar morphology which is difficult to identify in the field using the characteristic external morphology (Deng et al. 2016), including firefly. In addition, damaged external characteristics or incomplete samples of field-collected specimens causes difficulties for identification (Sumruayphol et al. 2016). High-efficiency molecular techniques can be used for firefly identification, such as DNA barcoding methods (Raupach et al. 2016), but are limited by being very expensive and requiring expertise (Peña et al. 2012). Therefore, there is a need for alternative methods for identifying species of a firefly which complement morphological identification.

Geometric morphometrics (GM) is a modern technique for studying shape and size variation that has two popular methods, landmark-based and outline-based GM (Dujardin 2011). The advantage of GM is that it is a cheap method which does not require much equipment, is easy to use and is rapid (Rohlf 2002). Currently, both GM methods have been applied to the study of entomology, including mosquito (Chaiphongpachara 2018; Chaiphongpachara et al. 2019), beetle (Lamb et al. 2013), blow-fly (Sontigun et al. 2017), spider (Fernández and Marugán 2017), pupae of flies (Chaiphongpachara and Laojun 2019), and bee (De Souza et al. 2015). Although it is an effective alternative tool, not all organisms can be identified by this technique, so it is necessary to study the feasibility of applying it to each organism (Ruangsittichai et al. 2011). 


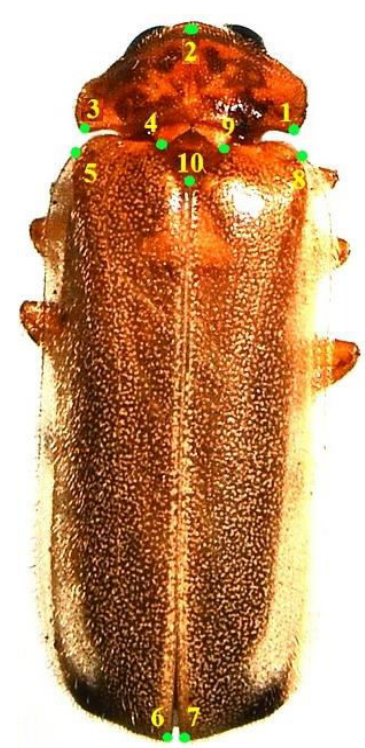

A

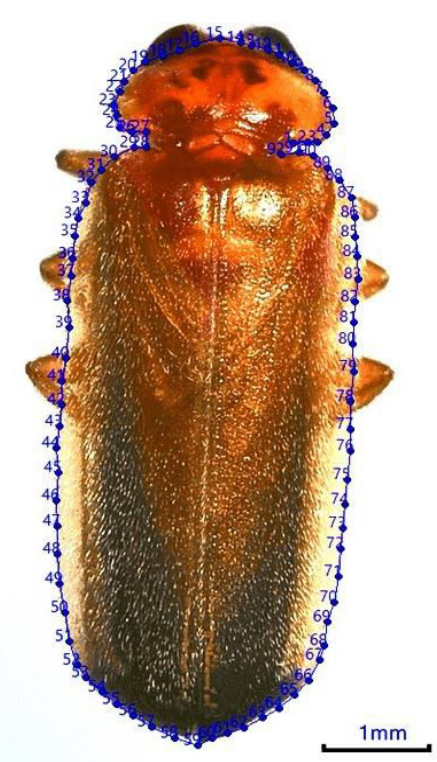

B
Figure 1. Ten landmarks on the firefly body for landmark-based GM (A) and external contour of firefly for outline-based GM method (B)

Based on all the above information and problems, this research involves a study of both landmark-based and outline-based GM techniques to discriminate each type of firefly in Samut Songkham, the relatively high number of fireflies in this province in Thailand. This study aims to address difficulties in the classification of fireflies, which represent an important ecological organism.

\section{MATERIALS AND METHODS}

\section{Firefly collection}

The collection of fireflies was conducted during the rainy season in August to October 2015 in three districts of Samut Songkham province, Thailand, including Muang Samut Songkham $\left(13^{\circ} 22^{\prime} 22.3^{\prime \prime N}, 9^{\circ} 58^{\prime} 10.1 " \mathrm{E}\right)$, Bang Khonthi $\left(13^{\circ} 28^{\prime} 21.0^{\prime \prime} \mathrm{N}, 9^{\circ} 58^{\prime} 11.2^{\prime \prime} \mathrm{E}\right)$ and Amphawa district $\left(13^{\circ} 24^{\prime} 42.7^{\prime \prime} \mathrm{N}, 9^{\circ} 56^{\prime} 56.4^{\prime \prime} \mathrm{E}\right)$. Only fireflies in the adult stage were collected, using an insect net once every two weeks during the three-month period, between 19:00 h and 21:00 h. Samples were transported to the laboratory at the College of Allied Health Science, Suan Sunandha Rajabhat University, Samut Songkhram center. Once firefly specimens arrived, they were then transferred to a$20{ }^{\circ} \mathrm{C}$ freezer awaiting morphological identification.

\section{Morphological firefly identification}

All fireflies were morphologically identified to species level using several illustrated keys, including Ballantyne and Lambkin (Ballantyne and Lambkin 2009; Ballantyne and Lambkin 2013), Wattanachaiyingcharoen and Nakeiam (Nak-Eiam et al. 2011) and Thancharoen et al. (2007). Fireflies were then photographed using a Nikon DS-Ri1 SIGHT digital camera connected to a Nikon AZ 100M stereo-microscope (Nikon Corp., Tokyo, Japan) and put alongside a 1-mm scale bar. In the analysis, both landmarkbased and outline-based GM approaches used the same set of the image, but the number may differ due to the removal of incomplete images from the GM analysis.

\section{Landmark-based geometric morphometric analysis}

Before conducting the analyses, the repeatability test was used to assess the quality of the digitized landmarks (landmark-based GM) and pseudo-landmarks (outlinebased GM) based on an ANOVA design (Dujardin 2011). Ten images of each species and sex of firefly (total is 60 images including female and male of $L$. aquatilis, $P$. valida, $P$. malaccae) were randomly chosen for repeatability testing.

Ten landmark indicators on the firefly body were digitized for creating coordinates (Figure1.A) and were selected from the key layout positions and easy to place. The body size was centroid size (CS), derived from the square root of the sum of the squared distances between the center of the configuration of landmarks and each individual landmark (Bookstein 1991). Body CS and shape variables (Partial warp, $[\mathrm{PW}]$ ) were generated from the Procrustes superposition according to the Generalized Procrustes Superimposition (GPA) process (Rohlf and Slice 1990). Discriminant analysis (DA) was used to analyze the shape variables for distinguishing each type of firefly. Differences in body shape between species of firefly were calculated based on Mahalanobis distance. Statistically significant differences in body size and shape between species of firefly were estimated based on nonparametric permutation tests (1000 runs). After, validated reclassification was estimated for accuracy of each species identification by GM based on the Mahalanobis distances. Finally, a neighbor-joining tree was constructed based on Procrustes distances between species of fireflies. All procedures were performed using the free program of geometric morphometric analysis.

\section{Outline-based geometric morphometric analysis}

The outline was the external contour of the body of firefly (Figure 1.B). The perimeter of contour was used to evaluate body size. Elliptic Fourier analysis (EFA) was used to construct shape variables (Kuhl and Giardina 1982) and A non-parametric test was used to compare the body size between species of firefly. After that, discriminant analysis (DA) illustrated the factor maps, separating each species of firefly. The Mahalanobis distance was then calculated to determine body shape difference between species of fireflies. The difference in size and shape of fireflies was tested by non-parametric permutation $(1,000$ runs), and testing accuracy was tested by validated reclassification. Finally, a neighbor-joining tree was constructed based on Procrustes distances in the same way as for the landmark-based method.

\section{Software}

Data analysis and graphical output were performed using CLIC package version 97 (Collecting Landmarks for Identification and Characterization), which is freely available at http://xyom-clic.eu/ (Dujardin 2008). Five Modules for landmark-based GM (COO, TET, MOG, 
FOG, VAR and PAD) and five Modules for outline-based GM (COO, TET, FOG, VAR and PAD) within CLIC package were used for GM analysis. The COO module to digitize the landmarks or pseudo-landmarks and transform the data for analysis by TET module. The MOG (landmark analysis) and FOG (pseudo-landmark analysis) modules were used and calculated to construct the size and shape variables, perform principal component analyses (PCA) and DA, compute Procrustes distances, and create quantile plots, respectively. The VAR module was used to analyze statistical significance of differences in the size variables among species, while differences in the shape variables among species were analyzed by PAD module.

\section{RESULTS AND DISCUSSION}

Samples of fireflies were collected in Samut Songkham province, Thailand. After morphological identification, three genera and four species of firefly were identified, including Luciola aquatilis Thancharoen, Pteroptyx valida Olivier, Pteroptyx malaccae Gorham, and Pyrocoelia praetexta Olivier. A total of 200 and 157 firefly images from these four species were used for landmark-based and outline-based analysis, respectively (Table 1).

\section{Repeatability}

The images sets of repeated measurements from the same images used in GM analyses showed good repeatability scores. In the landmark-based analysis, the repeatability score of the CS was 0.98 and outline-based analysis, the repeatability of the perimeter length was 0.94 .

\section{Landmark-based GM analysis}

Size variation of fireflies

The mean CS of female and male L. aquatilis, $P$. valida, $P$. malaccae and $P$. praetexta, derived from landmark-based GM analysis, showed size variation (Figure 2). The largest mean body size was found in male $P$. praetexta $(9.80 \mathrm{~mm})$, while female $P$. malaccae had the smallest mean CS $(7.02 \mathrm{~mm})$. There were significant difference $(p<0.05)$ in the three pairs of body size including female $L$. aquatilis with male $P$. praetexta, female $P$. valida with male $L$. aquatilis, and female $P$. valida with male $P$. valida ( $p>0.05$; Table 2).

\section{Shape variation of fireflies}

After Procrustes superposition using landmark-based $\mathrm{GM}$, polygons of mean body shape of each type of firefly were determined and are shown in Figure 3. The polygons visualized the difference of body shape in overlapping positions which were not within the line of each type of firefly (Figure 3).

The factor maps of discriminant analysis (DA) of fireflies derived from landmark-based GM are shown in Figure 4. Landmark-based DA of female fireflies presented overlap between $P$. valida and $P$. malaccae, but they were clearly separate from L. aquatilis (Figure 4.A). While male fireflies showed quite a few overlaps in 3 species, they were clearly separated from male $P$. praetexta (Figure 4.B).
Although male $P$. praetexta showed differences to other species, as few samples $(n=3)$ were available they were excluded from the shape analysis. The body shape showed a significant difference between all types of fireflies by the non-parametric test (1000 runs) using the pairwise Mahalanobis distances $(p<0.05$; Table 3$)$.

\section{Outline-based GM analysis}

Size variation of fireflies

The mean size of female and male L. aquatilis, $P$. valida, $P$. malaccae and $P$. praetexta derived from outlinebased GM analysis showed size variation (Figure 5). The largest mean body size was found in male $P$. praetexta (23.06 mm), while female $P$. malaccae had the smallest mean size $(15.94 \mathrm{~mm})$. Almost all pairs were significantly different from each group $(p<0.05)$, except three pairs which included female $L$. aquatilis with male $P$. praetexta, male $P$. valida with male $P$. praetexta, and female $P$. valida with male $P$. valida $(p>0.05$; Table 4$)$.

\section{Shape variation of fireflies}

After procrustes superposition of outlines of female and male fireflies is shown in Figure 6. The factor maps of discriminant analysis (DA) of fireflies, derived from outline-based GM, are shown in Figure 7. The outlinebased DA of the female firefly presented overlap of $P$. valida and $P$. malaccae, but they were clearly separated from L. aquatilis (Figure 7.A). Male fireflies showed clear separation of all types (Figure 7.B). The body shape showed significant difference between all types of firefly by non-parametric test (1000 runs) using the pairwise Mahalanobis distances $(p<0.05$; Table 5).

Table 1. Number of fireflies used for GM analysis

\begin{tabular}{llcc}
\hline \multirow{2}{*}{ Genus/species and sex } & \multicolumn{2}{c}{ Number of fireflies } \\
\cline { 3 - 4 } & & $\begin{array}{c}\text { Landmark-based } \\
\text { GM }\end{array}$ & $\begin{array}{c}\text { Outline-based } \\
\text { GM }\end{array}$ \\
\hline L. aquatilis & Female & 22 & 21 \\
& Male & 71 & 40 \\
P. malaccae & Female & 21 & 20 \\
& Male & 22 & 21 \\
P. valida & Female & 20 & 20 \\
& Male & 41 & 32 \\
P. praetexta & Male & 3 & 3 \\
& Total & 200 & 157 \\
\hline
\end{tabular}

Table 2. Statistical analysis of mean CS of fireflies

\begin{tabular}{llcc}
\hline \multirow{2}{*}{ Sex/genus and species } & \multicolumn{2}{c}{ Landmark-based GM method } \\
\cline { 3 - 4 } & $\begin{array}{c}\text { Mean } \mathbf{~ S D} \\
(\mathbf{m m})\end{array}$ & $\begin{array}{c}\text { Range } \\
(\mathbf{m i n}-\mathbf{m a x})\end{array}$ \\
\hline Female & L. aquatilis & $9.79 \pm 0.46^{\mathrm{a}}$ & $8.91-10.97$ \\
& $P$. malaccae & $7.02 \pm 0.43^{\mathrm{b}}$ & $6.17-7.68$ \\
Male & P. valida & $8.73 \pm 0.72^{\mathrm{c}, \mathrm{d}}$ & $6.36-9.57$ \\
& L. aquatilis & $8.66 \pm 0.59^{\mathrm{c}}$ & $7.49-11.02$ \\
& P. malaccae & $7.55 \pm 0.59^{\mathrm{e}}$ & $6.41-9.41$ \\
& P. valida & $8.97 \pm 0.62^{\mathrm{d}}$ & $7.11-10.48$ \\
& P. praetexta & $9.80 \pm 0.18^{\mathrm{a}}$ & $9.59-9.95$ \\
\hline
\end{tabular}

Note: Groups with different superscript letters indicate significant difference at $p<0.05$, Min: minimum; Max: maximum; mm: millimeter; Mean: average centroid size and average perimeter; SD: standard deviation 
Table 3. Mahalanobis distances between body shapes of firefly from landmark-based GM analysis

\begin{tabular}{|c|c|c|c|c|c|c|}
\hline \multirow[b]{3}{*}{$\begin{array}{l}\text { Sex/genus and } \\
\text { species }\end{array}$} & \multicolumn{6}{|c|}{$\begin{array}{l}\text { Mahalanobis distance of } \\
\text { landmark-based GM }\end{array}$} \\
\hline & \multicolumn{3}{|c|}{ Female } & \multicolumn{3}{|c|}{ Male } \\
\hline & 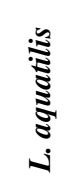 & 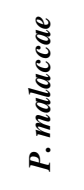 & 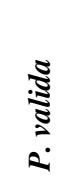 & 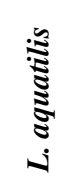 & 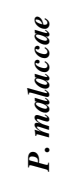 & 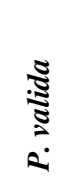 \\
\hline \multicolumn{7}{|l|}{ Female } \\
\hline L. aquatilis & 0.00 & & & & & \\
\hline P. malaccae & 5.56 & 0.00 & & & & \\
\hline P. valida & 5.12 & 3.01 & 0.00 & & & \\
\hline \multicolumn{7}{|l|}{ Male } \\
\hline L. aquatilis & 2.56 & 5.44 & 4.20 & 0.00 & & \\
\hline P. malaccae & 6.60 & 2.63 & 4.69 & 6.34 & 0.00 & \\
\hline P. valida & 4.62 & 2.81 & 2.13 & 3.97 & 3.99 & 0.00 \\
\hline
\end{tabular}

Note: * All pairwise Mahalanobis distances were statistically significant at $p<0.05$

Table 4. Statistical analysis of mean perimeter of firefly

\begin{tabular}{llllc}
\hline \multirow{2}{*}{ Sex/genus and species } & \multicolumn{3}{c}{ Outline-based GM method } \\
\cline { 3 - 5 } & $\mathbf{n}$ & $\begin{array}{c}\text { Mean } \pm \text { SD } \\
(\mathbf{m m})\end{array}$ & $\begin{array}{c}\text { Range } \\
(\mathbf{m i n}-\mathbf{m a x})\end{array}$ \\
\hline Female & L. aquatilis & 21 & $22.41 \pm 1.40^{\mathrm{a}}$ & $20.50-25.90$ \\
& P. malaccae & 20 & $15.94 \pm 0.87^{\mathrm{b}}$ & $14.55-17.22$ \\
\multirow{4}{*}{ Male } & P. valida & 20 & $20.48 \pm 1.77^{\mathrm{c}}$ & $14.81-22.50$ \\
& L. aquatilis & 40 & $19.33 \pm 1.19^{\mathrm{d}}$ & $16.28-22.08$ \\
& P. malaccae & 21 & $17.00 \pm 0.97^{\mathrm{e}}$ & $15.42-18.53$ \\
& P. valida & 32 & $21.21 \pm 2.13^{\mathrm{c}, \mathrm{f}}$ & $18.59-28.93$ \\
& P. praetexta & 3 & $23.06 \pm 1.25^{\mathrm{a}, \mathrm{f}}$ & $21.81-24.33$ \\
\hline
\end{tabular}

Note: Groups with different superscript letters indicate significant difference at $p<0.05$, Min: minimum; Max: maximum; $\mathrm{mm}$ : millimeter; Mean: average centroid size and average perimeter; SD: standard deviation

Table 5. Mahalanobis distances between body shapes of firefly using outline-based GM analysis

\begin{tabular}{|c|c|c|c|c|c|c|}
\hline \multirow[b]{3}{*}{ Sex/genus and species } & \multicolumn{6}{|c|}{$\begin{array}{c}\text { Mahalanobis distances of } \\
\text { outline-based GM }\end{array}$} \\
\hline & \multicolumn{3}{|c|}{ Female } & \multicolumn{3}{|c|}{ Male } \\
\hline & 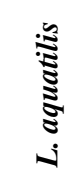 & 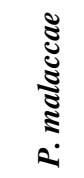 & 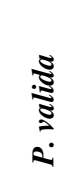 & 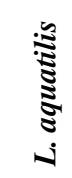 & 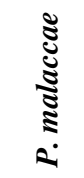 & 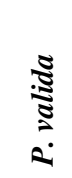 \\
\hline \multicolumn{7}{|l|}{ Female } \\
\hline L. aquatilis & 0.00 & & & & & \\
\hline P. malaccae & 5.08 & 0.00 & & & & \\
\hline P. valida & 5.11 & 3.50 & 0.00 & & & \\
\hline \multicolumn{7}{|l|}{ Male } \\
\hline L. aquatilis & 3.00 & 6.66 & 6.50 & 0.00 & & \\
\hline P. malaccae & 6.04 & 3.67 & 5.94 & 7.57 & 0.00 & \\
\hline P. valida & 6.60 & 5.90 & 5.46 & 7.80 & 4.82 & 0.00 \\
\hline
\end{tabular}

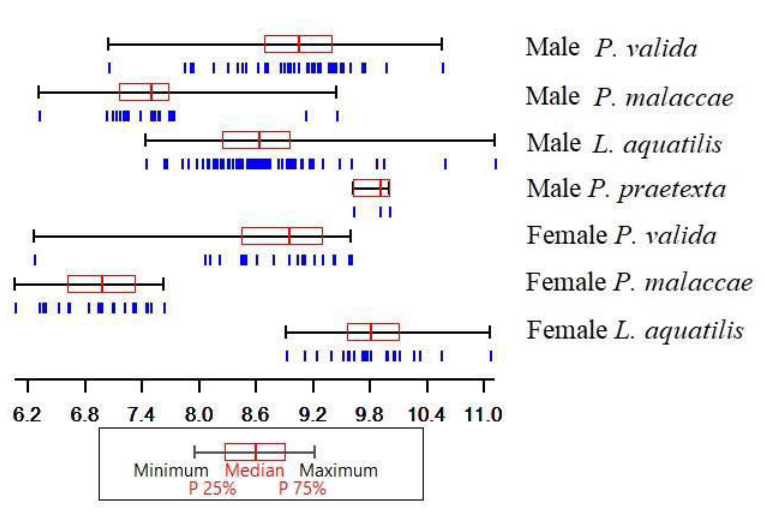

Figure 2. Body size variation of fireflies using the landmarkbased method. Vertical bar represents the size of the individual. Each quantile box shows the group median that separates 25 th and 75th quartiles

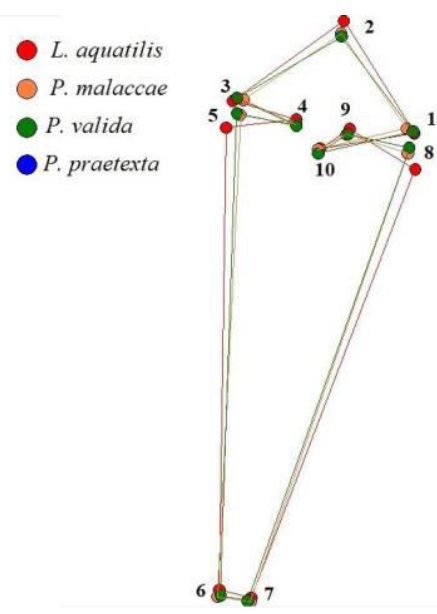

$\mathbf{A}$

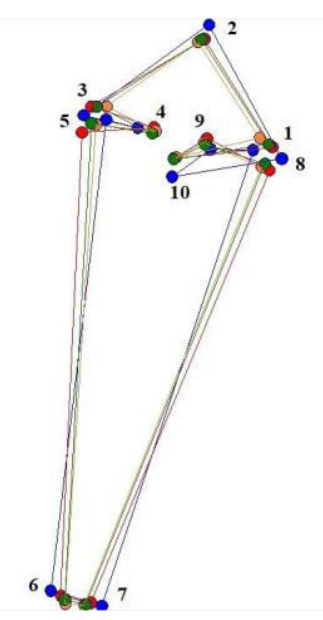

B
Figure 3. Superposition of the mean landmark configurations of female (A) and male (B) of firefly using landmark-based GM

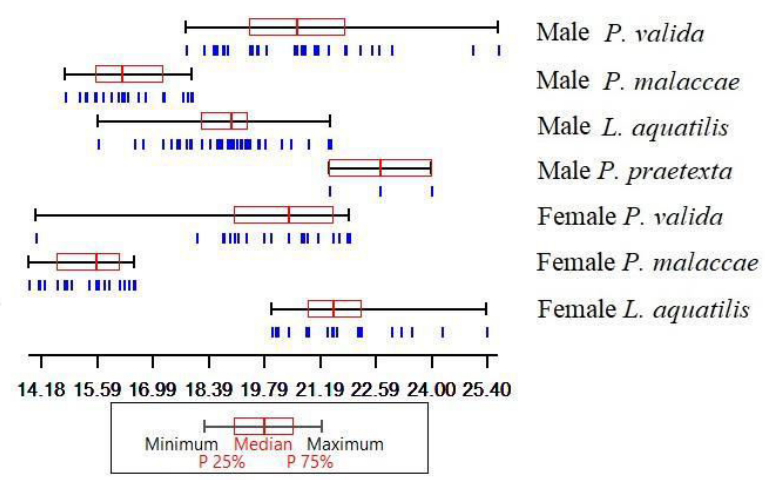

Figure 5. Body size variation of fireflies using the outline-based method. The vertical bar represents the size of the individual firefly. Each quantile box shows the group median that separates 25 th and 75 th quartiles. 


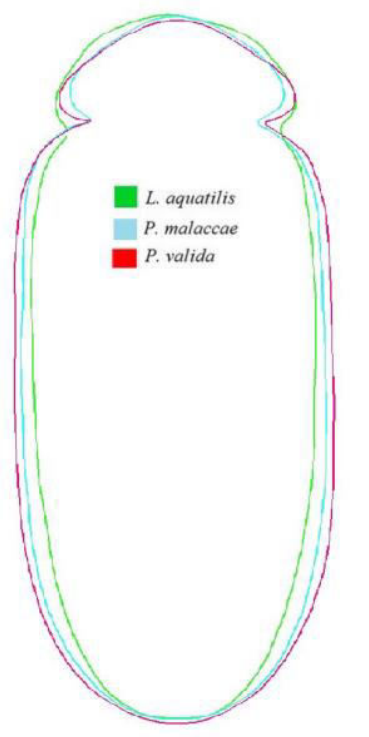

A

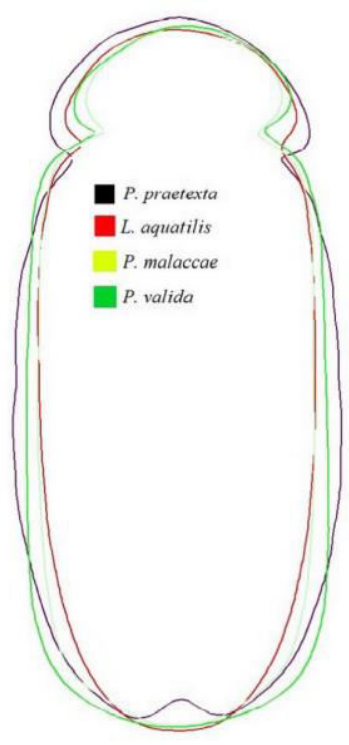

B
Validated reclassification scores confirmed the separation of each type of firefly, with both methods showing slightly different scores. Outline-based GM represented higher reclassification scores than landmarkbased GM. The landmark-based GM method provided 75\% to $95 \%$ of females, while the outline-based GM method provided $85 \%$ to $95 \%$. The highest reclassification scores for females were obtained in L. aquatilis with $95 \%$ with both GM methods of analysis (Table 6). Moreover, the outline-based GM method had a very high percentage in the separation of males. It provided $93 \%$ to $100 \%$ of males, while the landmark-based method provided $86 \%$ to $92 \%$.

Neighbor-joining trees based on Procrustes distances using landmark-and outline-based analyses of fireflies are shown in Figure 8. According to the landmark-based NJ tree, female and male L. aquatilis and P. malaccae were very close. Similarly, with the outline-based method, female and male P. malaccae were close. However, female and male $P$. valida were less close than other groups using landmark-and outline-based GM methods.

Figure 6. Superposition of outlines of female (A) and male (B) fireflies using outline-based GM

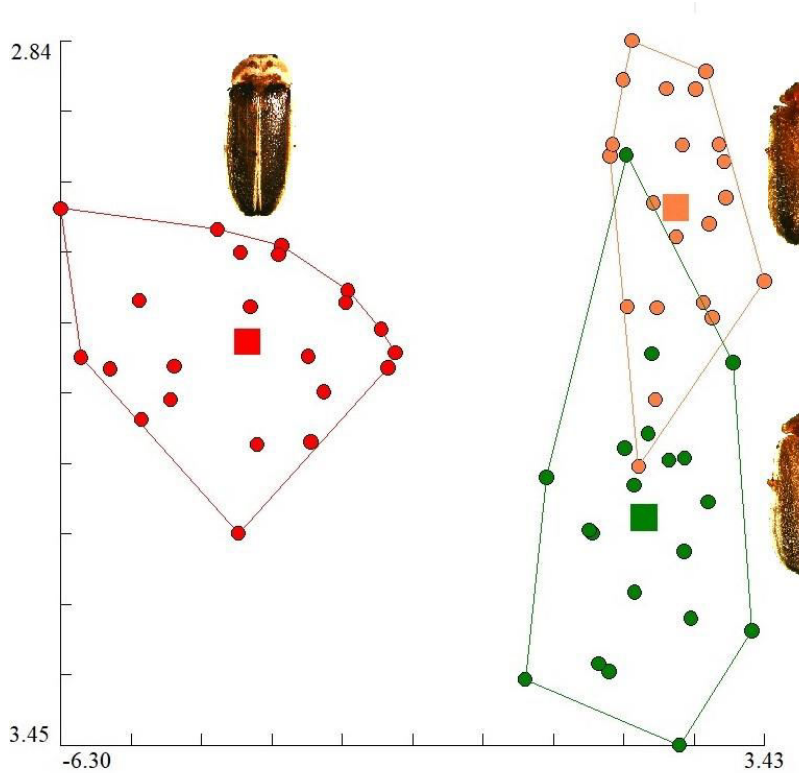

A

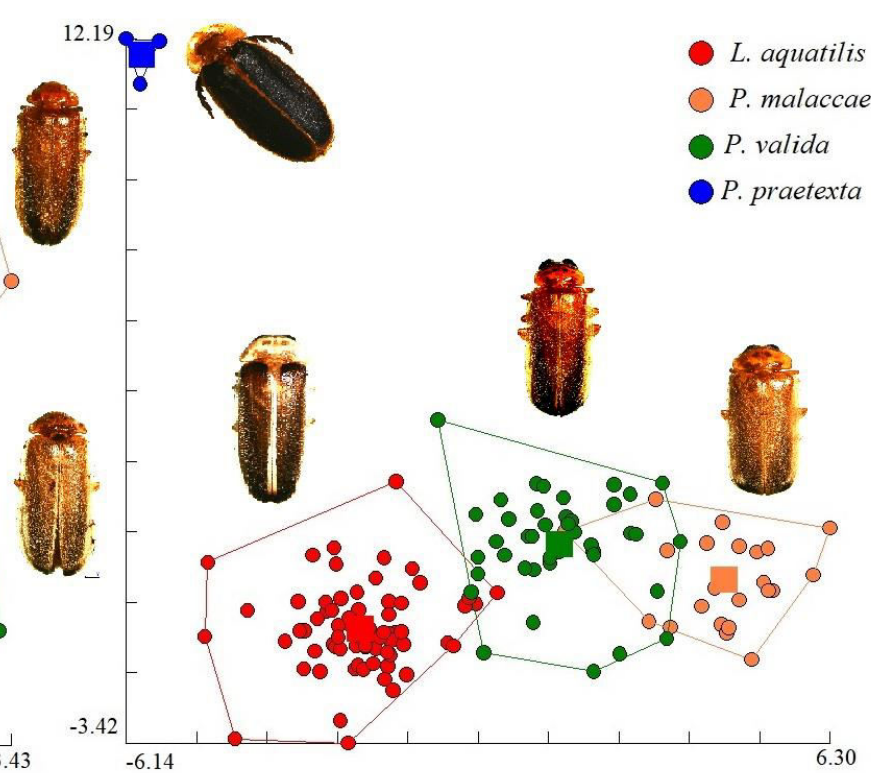

Figure 4. Factor map derived from female (A) and male fireflies (B) in each type of landmark-based GM discriminant analysis for $L$. aquatilis (Red), P. malaccae (Orange), P. valida (Green) and P. praetexta (Blue)

Table 6. Validated reclassification scores of fireflies based on landmark-and outline-based GM methods

\begin{tabular}{|c|c|c|c|c|}
\hline \multirow{3}{*}{ Genus/species } & \multicolumn{4}{|c|}{ Percentage of reclassification scores (assigned/observed) } \\
\hline & \multicolumn{2}{|c|}{ Landmark-based GM method } & \multicolumn{2}{|c|}{ Outline-based GM method } \\
\hline & Female & Male & Female & Male \\
\hline L. aquatilis & $95 \%(21 / 22)$ & $95 \%(68 / 71)$ & $95 \%(20 / 21)$ & $95 \%(38 / 40)$ \\
\hline P. malaccae & $85 \%(18 / 21)$ & $86 \%(19 / 22)$ & $90 \%(18 / 20)$ & $100 \%(21 / 21)$ \\
\hline P. valida & $75 \%(15 / 20)$ & $87 \%(36 / 41)$ & $85 \%(17 / 20)$ & $93 \%(30 / 32)$ \\
\hline
\end{tabular}




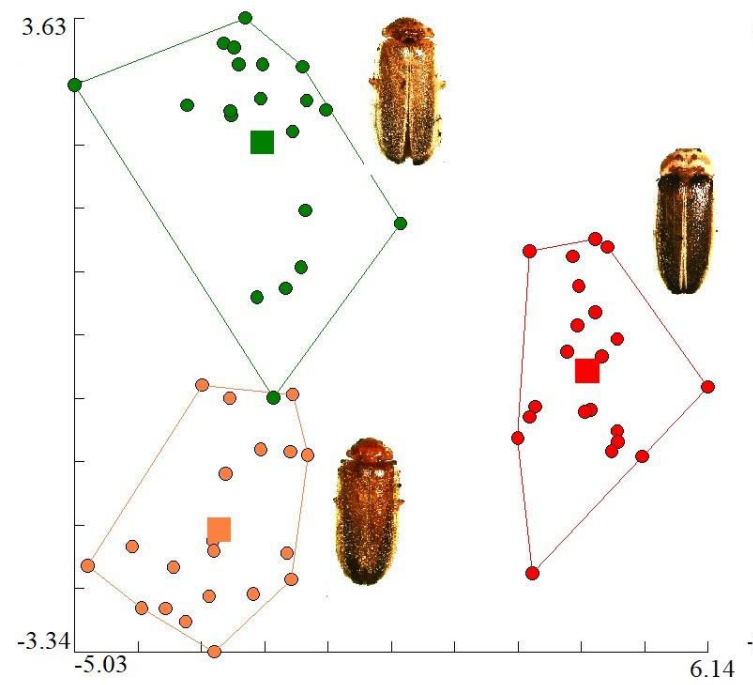

A

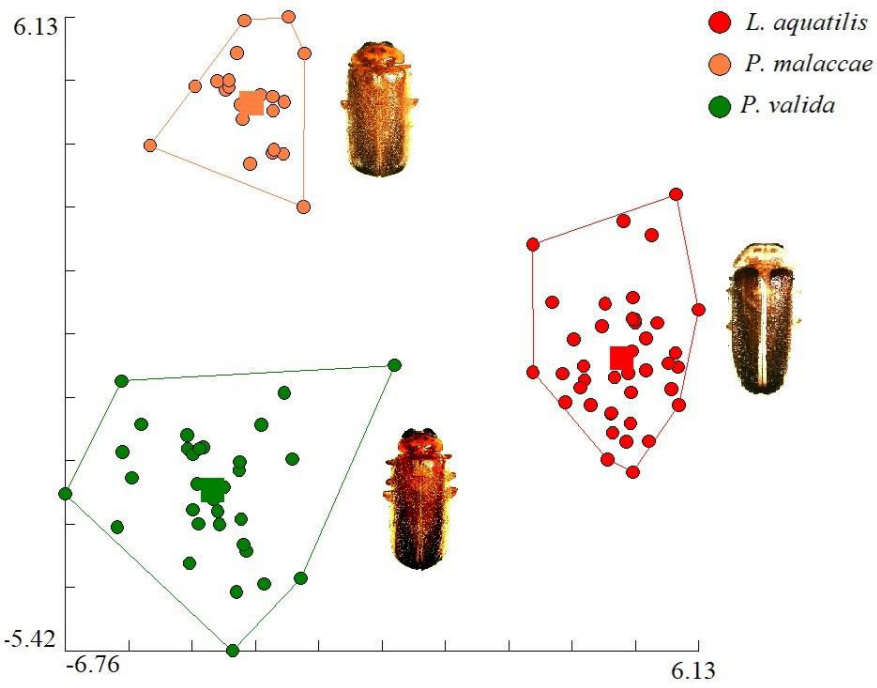

B

Figure 7. Factor map derived from female (A) and male fireflies (B) of each type using outline-based GM discriminant analysis for $L$. aquatilis (Red), P. malaccae (Orange), $P$. valida (Green) and $P$. praetexta (Blue)

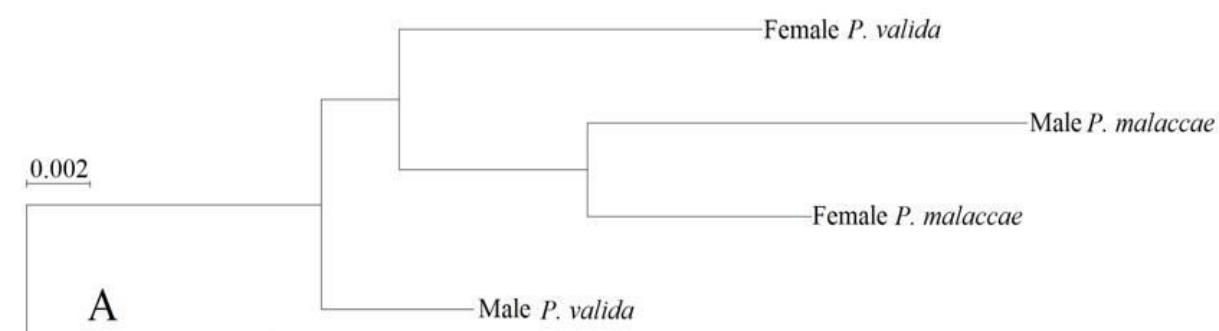

Female L. aquatilis

Male L. aquatilis

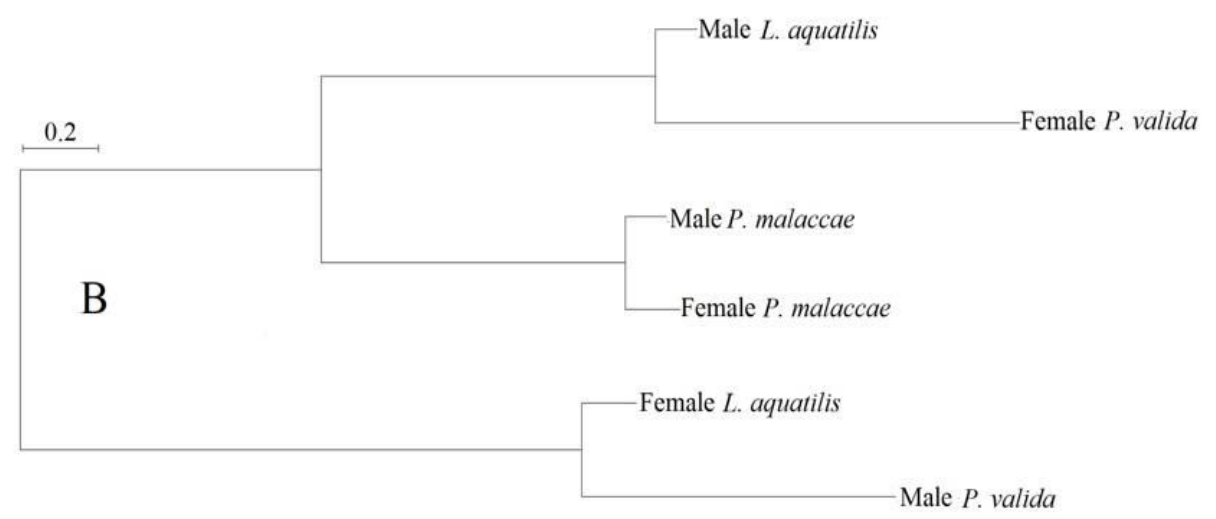

Figure 8. Neighbor-joining tree of landmark-(A) and outline-based (B) analyses of each type of firefly

\section{Discussion}

In this study, we found three genera and four species of firefly, namely $P$. valida, $P$. malaccae, $L$. aquatilis, and $P$. praetexta. The size variation of fireflies was analyzed in all species, but shape variation was analyzed in only three species as there were few samples of $P$. praetexta and they were excluded from the shape analysis using both GM methods.

Usually, diagnosis identification of morphological features of L. aquatilis is "brownish dorsal coloration with 
dark regions present at base and apex of elytra, elytral punctation of lines, sclerites associated with aedeagal sheath, and shape of the aedeagal sheath" (Thancharoen et al. 2007). While $P$. valida and P. malaccae are "the bipartite light organ of ventrite 7 occurs in those species in which the posterolateral projections and separates both species by concave emarginations from the median posterior projection as in $P$. malaccae and rounded, scarcely produced posteriorly, with scarce emarginations in P. valida" (Ballantyne 2015). Although, they are a morphological difference in appearance. However, there is a problem with distinguishing between each species of firefly in the field, caused by damage to the organs, causing the important pattern for identification to disappear.

\section{Size variation of fireflies}

Both landmark-based and outline-based GM analysis showed that size variation between two pairs was not statistically significant, including female $L$. aquatilis with male $P$. praetexta, and female $P$. valida with male $P$. valida. While other pairs of tested fireflies showed a significant difference, except male $P$. valida with male $P$. praetexta which was not significantly different, using outline-based GM. Results of both GM analyses indicate that males of $P$. valida and $P$. malaccae are slightly larger than females, while in L. aquatilis the female is larger than the male. This is consistent with the study of Ballantyne (Ballantyne and Menayah 2002), who reported on $P$. valida. While Thancharoen et al. (2007) reported on the long and wide size of L. aquatilis, similar to results of this study. Moreover, there are reports of different sizes of insects, such as mosquito and fly, that are associated with many factors including temperature, humidity, and food quality or quantity (Parker and Johnston 2006). Previous research on the identification of insects using GM has suggested that shape is more relevant than size in morphologically similar species (Ruangsittichai et al. 2011; Sumruayphol et al. 2016), as shape is one of the expressions of genetic background.

\section{Shape variation of fireflies}

Both landmark-based and outline-based GM methods can distinguish between the specific shape of each firefly type with a high degree of accuracy, especially outlinebased GM method. Females and males of $L$. aquatilis are clearly separated by landmark-based GM, but both $P$. valida and $P$. malaccae are not good with the group separation. This may be because of the landmark positions on the firefly body used for analysis showed no differences between the two Pteroptyx species. $P$. valida and $P$. malaccae are members of the genus Pteroptyx, which are brackish aquatic fireflies that makes them similar in morphology and habitat (Sriboonlert et al. 2015). These morphological similarities present difficulties in distinguishing the two species. However, the factor maps of the outline-based GM analysis have demonstrated the separation of each group of fireflies well, including $P$. valida and $P$. malaccae. The reason is probably because of the shape of the firefly is unique. It was reported that a GM method, which involved pointing landmarks on the external outline, was used to determine the differences in fogbasking beetles, which were relatively well separated (Lamb et al. 2013). Unfortunately, the firefly samples in this analysis used in this analysis were fairly small in number, due to the limited access to the large rivers as their habitat. Nevertheless, it is important to generate information on the use of alternative methods to help in the identification of fireflies, particularly those species which have morphological similarities.

The reclassification scores were better for outline-based analysis than landmark-based analysis. In this study, the outline-based GM analysis provided the perfect reclassification scores $(100 \%)$ for male $P$. malaccae and high percentages of males $(>90 \%)$ and females $(>90 \%)$ in other types of firefly. Although the outline-based method has the ability to distinguish well, there are limits as it is time-consuming and requires many samples. Even though the landmark-based method showed less capacity for separation than the outline-based GM method, it has the advantage of being easy to use and requires fewer samples than outline-based GM methods. The landmark-based GM is quite interesting, and it is suitable for initial screening no less than outline-based GM (Dujardin 2011; Dujardin et al. 2014). According to our findings, the GM can be used to separate species of firefly with high efficiency. However, this research showed that both landmark-based and outlinebased GM methods make a useful contribution to the identification of firefly species.

In conclusion, fireflies are insects that are important to the ecosystem, generate income from tourism in the area and act as a biological control for snail, an intermediate hosts of trematode parasites. However, there are relatively few studies of fireflies in Thailand. With some fireflies, it is difficult to distinguish the species using standard methods because of similarities in morphology. These results show that GM methods can be complementary techniques for firefly identification, especially outlinebased GM methods. The advantages of GM are that it is a very fast method, easy to use, and inexpensive. Therefore, this method is one way to resolve difficulties in firefly identification and can be used to support future studies relating to fireflies.

\section{ACKNOWLEDGEMENTS}

We would like to thank all staff members and lecturers in the College of Allied Health Science, Suan Sunandha Rajabhat University, Thailand for their kind support of our research.

\section{REFERENCES}

Ballantyne LA, Lambkin C. 2009. Systematics of indo-pacific fireflies with a redefinition of Australasian atyphella Olliff, Madagascan photuroluciola pic, and description of seven new genera from the Luciolinae (Coleoptera: Lampyridae). Zootaxa 1-188. DOI: 10.11646/zootaxa.1997.1.1

Ballantyne LA, Lambkin CL. 2013. Systematics and phylogenetics of indo-pacific Luciolinae fireflies (coleoptera: lampyridae) and the description of new genera. Zootaxa 3653 (1): 1-162. 
Ballantyne LA, Menayah R. 2002. A description of larvae and redescription of adults of the firefly Pteroptyx valida Olivier in Selangor, Malaysia (Coleoptera: Lampyridae: Luciolinae), with notes on Luciolinae larvae. Raffles B Zool 50: 101-109.

Bookstein FL. 1991. Morphometric tools for landmark data: geometry and biology. Cambridge University Press. United Kingdom.

Bousquet Y. 1991. Checklist of beetles of Canada and Alaska. Zookeys 360: 1-44.

Chaiphongpachara T. 2018. Comparison of landmark-and outline-based geometric morphometrics for discriminating mosquito vectors in Ratchaburi Province, Thailand. Biomed Res Int Article ID 6170502.

Chaiphongpachara T, Sriwichai P, Samung Y, Ruangsittichai J, Morales Vargas RE, Cui L, Sattabongkot J, Dujardin JP, Sumruayphol S. 2019. Geometric morphometrics approach towards discrimination of three-member species of Maculatus group in Thailand. Acta Trop. 192: 66-74.

Chaiphongpachara T, Laojun S. 2019. Geometric morphometry of pupae to identify four medically important flies (Order: Diptera) in Thailand. Biodiversitas 20(6): 1504-1509.

De Souza DA, Wang Y, Kaftanoglu O, De Jong D, Amdam GV, Gonçalves LS, Francoy TM. 2015. Morphometric identification of queens, workers, intermediates in vitro reared honey bees (Apis mellifera). PLoS ONE 10(4): e0123663

Deng J, Li K, Chen C, Wu S, Huang X. 2016. Discovery pattern and species number of scale insects (Hemiptera: Coccoidea). Peer J 4 e2526. DOI: $10.7717 /$ peerj. 2526 .

Dujardin JP. 2008. Morphometrics applied to medical entomology. Infect Genet Evol 8: 875-890.

Dujardin JP. 2011. Modern morphometrics of medically important insects. Infect Genet Evol 124: 473-501. DOI: 10.1016/b978-0-12-384890$1.00016-9$

Dujardin JP, Kaba D, Solano P, Dupraz M, McCoy KD, Jaramillo-O N. 2014. Outline-based morphometrics, an overlooked method in arthropod studies. Infect Genet Evol 28: 704-714.

Dujardin JP, Al Kaba D, Henry AB. 2010. The exchangeability of shape. BMC Res Notes 3: 266.

Fernández-Montraveta C, Marugán-Lobón J. 2017. Geometric morphometrics reveals sex-differential shape allometry in a spider. PeerJ 5:e3617. DOI: 10.7717/peerj.3617.

Foo K, Dawood MM, Kinabalu K. 2015. Diversity of fireflies (Coleoptera : Lampyridae) of Sungai. J Trop Biol Conserv 12: 1-11.

Fu X, Benno Meyer-Rochow V. 2013. Larvae of the firefly Pyrocoelia pectoralis (Coleoptera: Lampyridae) as possible biological agents to control the land snail Bradybaena ravida. Biol Control 65:176-183.

Goh KS, Sheu HS, Hua TE, Kang MH, Li CW. 2013. Uric Acid Spherulites in the Reflector layer of firefly light organ. PLoS ONE 8(2): e56406. DOI:10.1371/journal.pone.0056406.

Kuhl FP, Giardina CR. 1982. Elliptic Fourier features of a closed contour. Com Graps Image Processing 18: 236-258.

Lamb T, Pollard R, and Bond JE. 2013. Genetic variation corroborates sub specific delimitation in the Namib fog-basking beetle, Onymacris unguicularis (Haag) (Tenebrionidae, Coleoptera). ZooKeys 353: 47 60 .

Madruga Rios O, Hernández Quinta M. 2010. Larval feeding habits of the Cuban endemic firefly Alecton discoidalis Laporte (Coleoptera: Lampyridae). Psyche 2010: 1-6.

Nak-Eiam S, Wattanachaiyingcharoen W, Thancharoen A. 2011. Distribution and habitat of the firefly, Asymmetricata circumdata (Motsch.) (Coleoptera: Lampyridae: Luciolinae) in the North of Thailand. NU Sci J 8: 12-18.

Nurancha P, Inkapatanakul W, Chunkao K. 2013. Guidelines to the management of firefly watching tour in Thailand. Mod Appl Sci 7: 814.

Parker J, Johnston LA. 2006. The proximate determinants of insect size. J Biol 5: 1-4.

Peña VH, Fernández GJ, Gómez-Palacio AM, Mejía-Jaramillo AM, Cantillo O, Triana-Chávez O. 2012. High-resolution melting (HRM) of the cytochrome B gene: A powerful approach to identify bloodmeal sources in Chagas disease vectors. PLoS Negl Trop Dis 6(2): e1530. DOI: 10.1371/journal.pntd.0001530.

Raupach MJ, Hannig K, Morinière J, Hendrich L. 2016. A DNA barcode library for ground beetles (Insecta, Coleoptera, Carabidae) of Germany: The genus Bembidion Latreille, 1802 and allied taxa. ZooKeys 2016: 121-141.

Rohlf FJ. 2002. Geometric morphometrics in systematics. In: Macleod N, Forey P (eds.). Morphology, Shape and Phylogenetics. Taylor \& Francis, London.

Rohlf FJ, Slice D. 1990. Extensions of the procrustes method for the optimal superimposition of landmarks. Syst Zool 39: 40-59.

Ruangsittichai J, Apiwathnasorn C, Dujardin JP. 2011. Interspecific and sexual shape variation in the filariasis vectors Mansonia dives and Ma. bonneae. Infect Genet Evol 11: 2089-2094.

Sontigun N, Sukontason KL, Zajac BK, Zehner R, Sukontason K, Wannasan A, Amendt J. 2017. Wing morphometrics as a tool in species identification of forensically important blow flies of Thailand. Parasit Vectors 10: 229.

Sriboonlert A, Swatdipong A, Wonnapinij P, E-Kobon T, Thancharoen A. 2015. New record of Pteroptyx tener Olivier (Coleoptera: Lampyridae: Luciolinae) in Thailand. Coleopt Bull 69: 332-336.

Sumruayphol S, Apiwathnasorn C, Ruangsittichai J, Sriwichai P, Attrapadung S, Samung Y, Dujardin JP. 2016. DNA barcoding and wing morphometrics to distinguish three Aedes vectors in Thailand. Acta Trop 159: 1-10.

Thancharoen A, Ballantyne LA, Branham MA, Jeng ML. 2007. Description of Luciola aquatilis sp. nov., a new aquatic firefly (Coleoptera: Lampyridae: Luciolinae) from Thailand. Zootaxa 1611: 55-62.

Wang Y, Fu X, Lei C, Jeng M, Nobuyoshi O. 2007. Biological characteristics of the terrestrial firefly Pyrocoelia pectoralis (Coleoptera: Lampyridae). Coleopt Bull 61: 85-93. 